\title{
Influence of dietary fat sources and conjugated fatty acid on egg quality, yolk cholesterol, and yolk fatty acid composition of laying hens
}

\author{
Moung-Cheul Keum ${ }^{1}$, Byoung-Ki An ${ }^{1}$, Kyoung-Hoon Shin ${ }^{1}$, Kyung-Woo Lee ${ }^{1 *}$
}

${ }^{1}$ Konkuk University, Department of Animal Science and Technology, Laboratory of Poultry Science, Seoul, Republic of Korea.

\begin{abstract}
This study was conducted to investigate the effects of dietary fats (tallow [TO] or linseed oil [LO]) or conjugated linoleic acid (CLA), singly or in combination, on laying performance, yolk lipids, and fatty acid composition of egg yolks. Three hundred 50 -week-old laying hens were given one of five diets containing 2\% TO; $1 \%$ TO + 1\% CLA (TO/CLA); $2 \%$ LO; $1 \% \mathrm{LO}+1 \% \mathrm{CLA}$ (LO/CLA); and 2\% CLA (CLA). Laying performance, egg lipids, and serum parameters were not altered by dietary treatments. Alpha-linolenic acid or long-chain $\omega-3$ fatty acids including eicosapentaenoic and docosahexaenoic acids were elevated in eggs of laying hens fed diets containing LO (i.e., LO or LO/CLA groups) compared with those of hens fed TO-added diets. Dietary CLA, alone or when mixed with different fat sources (i.e., TO or LO), increased the amounts of CLA in egg yolks, being the highest in the CLA-treated group. The supplementation of an equal portion of CLA and LO into the diet of laying hens (i.e., LO/CLA group) increase both CLA and $\omega-3$ fatty acid contents in the chicken eggs.
\end{abstract}

Key Words: lipid metabolism, linseed oil, $\omega-3$ fatty acids

\section{Introduction}

Chicken eggs are one of the most complete foods which contain high crude protein with well-balanced amino acids and substantial levels of vitamins, minerals, and other health-promoting compounds (Yamamoto et al., 1997). Recently, traditional assumptions that cholesterol from eggs or other food was unhealthy are no longer valid, as no association between egg consumption and the incidence of cardiovascular disease has been reported in recent studies (Zazpe et al., 2011; Miranda et al., 2015). In addition to the diet-induced decrease in the cholesterol level in egg yolk (Elkin, 2007), the modification of fatty acid profiles has proven to be a viable tool of producing enhanced eggs for health-conscious consumers (Hargis and Van Elswyk, 1993).

Conjugated dienoic derivatives of linoleic acid (CLA) are a series of positional and geometric isomers of linoleic acid (Hur et al., 2013a,b; Wang and Lee, 2015). Conjugated linoleic acid is found predominantly in products from ruminants, including milk, cheese, and beef (Bauman et al.,

Received: November 23, 2017 Accepted: February 20, 2018

*Corresponding author: kyungwoolee@konkuk.ac.kr

Copyright (C) 2018 Sociedade Brasileira de Zootecnia. This is an Open Access article distributed under the terms of the Creative Commons Attribution License (http://creativecommons.org/licenses/by/4.0/), which permits unrestricted use, distribution, and reproduction in any medium, provided the original work is properly cited.
2000; Wang et al., 2015). It has been reported (Ip et al., 1999; Yamasaki et al., 2000; Oh et al., 2014) that dietary CLA isomers have an anticarcinogenic effect and can modulate immune response with experimental animals. It is well known that foods derived from non-ruminant animals contain much less CLA than those from ruminants. Practically, it is widely accepted that adding CLA to a diet of laying hens can increase CLA contents in egg yolks (Chamruspollert and Sell, 1999; Jones et al., 2000).

In addition to CLA, consumption of $\omega-3$ fatty acids, i.e., $\alpha$-linolenic (ALA), eicosapentaenoic (EPA), and docosahexaenoic (DHA) acids, is considered to have healthpromoting effects in humans by lowering cardiovascular and inflammatory diseases (Elkin et al., 2015). It is well known that adding linseed oil (LO) or full-fat linseed (Phetteplace and Watkins, 1989; Olomu and Baracos, 1991), fish oil (Scaife et al., 1994), and fish meal (Hulan et al., 1989) as sources of $\omega-3$ fatty acids to the diet of chickens linearly increase the relative and absolute contents of $\omega-3$ polyunsaturated fatty acids (PUFA).

Thus, it would be of value if dietary origin of both $\omega-3$ PUFA and CLA could be incorporated into the chicken eggs, which prompted us to undertake the current experiment. We used two dietary fats (i.e., beef tallow [TO] and LO) or synthetic CLA, and evaluated their effects, single or in combination, on production traits, egg lipids and qualities, and fatty acid profiles in egg yolks. 


\section{Material and Methods}

The protocol for the experiment was approved by the Institutional Animal Care and Use Committee (case no. KU15186).

The experiment was conducted on an experimental farm in Chungju, Chungbuk-do, South Korea (36 $36^{\circ} 38^{\prime}$ N, $127^{\circ} 29^{\prime}$ E). Three hundred 50-week-old Hy-line Brown laying hens were housed in two-tier batter cages, three birds per cage, equipped with nipples and feeders. They were divided into five dietary treatments with four replicates of 15 birds per replicate (three birds per cage, five cages per replicate) and fed one of the five experimental diets (Table 1): 2\% tallow (TO, Cargill Agri Purina Inc., Korea); 1\% TO + 1\% CLA (The Rinoru Oil Mills Co. Ltd., Japan) (TO/CLA); $2 \%$ linseed oil (LO, Cargill Agri Purina Inc., Korea); $1 \%$ linseed oil + 1\% CLA (LO/CLA); and 2\% CLA (CLA). Ethoxyquin was added into the basal diet to prevent lipid peroxidation. A corn and soybean mealbased diet was used to formulate the experimental diets, and the inclusion levels of fats or CLA (Table 2), singly or blended, were set at $2 \%$ in diet. It was reasoned that higher fat inclusion so far published (An et al., 1997; Raes et al., 2002; Yin et al., 2008) is used to increase the treatment contrasts, but is not commonly used in layer diet formulation. All diets were formulated to meet and exceed the nutrient requirements of NRC (1994). The experiment lasted 28 days, and diets and water were provided for ad libitum intake. A room temperature of $24 \pm 3{ }^{\circ} \mathrm{C}$ and a photoperiod of $16 / 8 \mathrm{~h}$ light/dark cycle were maintained throughout the experimental period. The experimental diets were daily provided and feed intakes per replicate were weekly recorded.

Eggs laid per replicate were recorded daily and mean egg weight per replicate was determined. Abnormal eggs (i.e., shell-less) were discarded from the measurement. At the end of feeding trial, five eggs from each replicate were randomly selected, weighed individually and stored overnight at room temperature for egg quality measurements. The breaking strength of intact eggs was measured with an eggshell strength tester (FHK, Fujihara Ltd., Tokyo, Japan). Eggshell thickness without shell membrane was tested by micrometer (Digimatic micrometer, Series 293-330, Mitutoyo, Japan). Albumen height were measured by using egg multi tester made by TSS (Technical Services and Supplies Ltd., York, England), and egg yolk color was measured using Roche yolk color fan (Hoffman-La Roche Ltd., Basel, Switzerland). Haugh unit was calculated from egg weight and albumen height as indicated by Haugh (1937).
Six eggs per treatment close to mean egg weight were sampled at the end of the feeding trial. The contents of lipid fraction in the egg yolk were separated by thin layer chromatography on silica gel chromatorods using hexane: diethylether:formic acid (85:15:0.1; vol:vol) as developing

Table 1 - Formula and chemical composition of experimental diets

\begin{tabular}{lccccc}
\hline Ingredient $(\mathrm{g} / \mathrm{kg})$ & TO & TO/CLA & LO & LO/CLA & CLA \\
\hline Yellow corn & 586.7 & 586.7 & 586.7 & 586.7 & 586.7 \\
Corn gluten meal & 25.0 & 25.0 & 25.0 & 25.0 & 25.0 \\
Soybean meal & 167.0 & 167.0 & 167.0 & 167.0 & 167.0 \\
Wheat bran & 90.0 & 90.0 & 90.0 & 90.0 & 90.0 \\
Limestone & 93.0 & 93.0 & 93.0 & 93.0 & 93.0 \\
Dicalcium phosphate & 10.2 & 10.2 & 10.2 & 10.2 & 10.2 \\
Salt & 3.0 & 3.0 & 3.0 & 3.0 & 3.0 \\
Tallow & 20.0 & 10.0 & - & - & - \\
Linseed oil & - & - & 20.0 & 10.0 & - \\
Conjugated linoleic acid & - & 10.0 & - & 10.0 & 20.0 \\
Choline-chloride, 50\% & 1.0 & 1.0 & 1.0 & 1.0 & 1.0 \\
L-lysine HCl, 78\% $^{-1.0}$ & 1.2 & 1.2 & 1.2 & 1.2 & 1.2 \\
DL-methionine, $99 \%^{1} \%$ & 0.9 & 0.9 & 0.9 & 0.9 & 0.9 \\
Mineral mixture $^{1}$ & 1.0 & 1.0 & 1.0 & 1.0 & 1.0 \\
Vitamin mixture $^{2}$ & 1.0 & 1.0 & 1.0 & 1.0 & 1.0 \\
Total $^{2}$ & 1,000 & 1,000 & 1,000 & 1,000 & 1,000
\end{tabular}

Calculated analysis

Dry matter $(\mathrm{g} / \mathrm{kg})$

Crude protein $(\mathrm{g} / \mathrm{kg})$

Ether extract $(\mathrm{g} / \mathrm{kg}) \quad 48.2$

Crude fiber $(\mathrm{g} / \mathrm{kg}) \quad 32.8$

$\mathrm{Ca}(\mathrm{g} / \mathrm{kg}) \quad 38.0$

Available $\mathrm{P}(\mathrm{g} / \mathrm{kg}) \quad 3.0$

TMEn $(\mathrm{kcal} / \mathrm{kg})$

2,800

TMEn - nitrogen-corrected true metabolizable energy.

TO: $2 \%$ tallow in diet; TO/CLA: $1 \%$ tallow and $1 \%$ CLA in diet; LO: $2 \%$ linseed oil in diet; $\mathrm{LO} / \mathrm{CLA}: 1 \%$ linseed oil and $1 \%$ CLA in diet; CLA: $2 \%$ CLA in diet.

${ }^{1}$ Mineral mixture provided the following nutrients per kg of diet: Fe, $40 \mathrm{mg}$; $\mathrm{Zn}$, $65 \mathrm{mg}$; Mn, $87 \mathrm{mg}$; Cu, $66 \mathrm{mg}$; I, $1.5 \mathrm{mg}$; Se, $0.1 \mathrm{mg}$.

2 Vitamin mixture provided the following nutrients per $\mathrm{kg}$ of diet: vitamin A, 11,000 IU; vitamin D3, 2,250 IU, vitamin E, $11 \mathrm{mg}$; vitamin $\mathrm{K} 3,0.6 \mathrm{mg}$; vitamin B1, $1 \mathrm{mg}$; vitamin B2, $10 \mathrm{mg}$; vitamin B6, $1 \mathrm{mg}$; vitamin B12, $0.02 \mathrm{mg}$; niacin, $32.5 \mathrm{mg}$; pantothenic acid, $10 \mathrm{mg}$; biotin, $0.03 \mathrm{mg}$; folic acid, $0.5 \mathrm{mg}$; ethoxyquin, $1,650 \mathrm{mg}$.

Table 2 - Fatty acid compositions of fat sources used (\% of total fatty acids)

\begin{tabular}{|c|c|c|c|}
\hline Fatty acid $^{1}$ & TO & CLA & LO \\
\hline C14:0 & $29.97^{2}$ & 9.21 & 5.05 \\
\hline $\mathrm{C} 16: 1(\omega-7)$ & 2.94 & 0.14 & 0.08 \\
\hline C18:0 & 12.22 & 2.67 & 3.81 \\
\hline C18:1( $\omega-9)$ & 38.20 & 24.49 & 19.33 \\
\hline $\mathrm{C} 18: 2(\omega-6)$ & 9.48 & 4.72 & 14.71 \\
\hline $\mathrm{C} 18: 3(\omega-3)$ & 0.08 & 0.50 & 51.77 \\
\hline cis-9, trans-11 CLA & - & 24.70 & - \\
\hline trans- 10 , cis- 12 CLA & - & 26.45 & - \\
\hline $\mathrm{C} 20: 1(\omega-9)$ & 0.11 & 0.10 & 0.06 \\
\hline Total SFA & 44.24 & 11.98 & 8.91 \\
\hline Total MUFA & 41.25 & 24.73 & 19.47 \\
\hline Total PUFA & 9.56 & 56.37 & 66.48 \\
\hline
\end{tabular}

TO - tallow; CLA - conjugated fatty acid; LO - linseed oil; SFA - saturated fatty acids; MUFA - monounaturated fatty acids; PUFA - polyunsaturated fatty acids.

${ }^{1}$ Number of carbon atom: number of double bonds, followed by the position of the first double bond relative to the methyl end.

${ }^{2}$ Values are expressed as $\%$ of total fatty acids. 
solvents, and quantified by IATRO SCAN (TH-10 TLC/ FID analyzer, Iatron Laboratory Inc, Tokyo, Japan), with hydrogen as gas flow (An et al., 1997).

At the end of experiment, 10 birds per treatment were randomly selected, weighed, and killed by cervical dislocation. Immediately after euthanasia, blood was obtained by heart puncture. Then, liver was excised, weighed, and expressed as relative to live body weight. Serum samples were obtained by gentle centrifugation and stored at $-20{ }^{\circ} \mathrm{C}$ until use. The activities of serum glutamic oxaloacetic transaminase and glutamic pyruvic transaminase were measured according to the colorimetric method as previously described (An et al., 2003).

To determine weekly pattern of fatty acid composition of egg yolks, six eggs per treatment close to mean egg weight were sampled weekly for four weeks of the experiment. The total lipids were extracted from egg yolks using chloroform/methanol $(2: 1, \mathrm{v} / \mathrm{v})$ as described by Folch et al. (1957) and Wang et al. (2013). Extracted lipids were methylated according to the methods of Takenoyama et al. (1999) with minor modification. In brief, about $3 \mathrm{~mL}$ of sample was transesterified to fatty acid methyl esters in benzene using $0.5 \mathrm{M} \mathrm{KOH} / \mathrm{methanol}$ for $10 \mathrm{~min}$ at $100{ }^{\circ} \mathrm{C}$. After cooling, the turbid preparation was neutralized with $\mathrm{HCl} /$ methanol and then reheated. Fatty acid methyl esters were extracted with hexane and measured by gas-liquid chromatography (HP 5890 II Series, Hewlett-Packard, Atlanta, USA) using $0.32 \mathrm{~mm}$ I.D. $\times 60 \mathrm{~m}$ capillary column (SUPELCOWAX-10, Supelco Ltd., Pennsylvania, USA). The initial column temperature was initially programmed at $170{ }^{\circ} \mathrm{C}$ and increased to $220^{\circ} \mathrm{C}$ by $2{ }^{\circ} \mathrm{C} / \mathrm{min}$. The injector and detector were set at 250 and $260{ }^{\circ} \mathrm{C}$, respectively. The peaks were identified by comparing with standard mixture of fatty acid methyl esters (Lipid standard and Linoleic acid methyl ester, cis/trans-isomers, Sigma Ltd., St. Louis, USA). Identified fatty acids were expressed as a percentage of total fatty acids (Nile and Park, 2013).

Replicate was considered an experimental unit. Data were analyzed by the GLM procedure of the SAS
(Statistical Analysis System, version 9.4). The significant differences of obtained means were determined using Duncan's multiple range test at the level of $\mathrm{P}<0.05$.

\section{Results}

All parameters, i.e., laying performance, egg quality, egg yolk lipids, and blood components except for the fatty acid composition in egg yolks were not affected $(\mathrm{P}>0.05)$ by dietary treatments (Tables 3,4 , and 5 ).

In general, fatty acid composition of egg yolk was readily altered at one week of feeding the experimental diets and kept constant thereafter (Tables 6 and 7). Oleic acid was the predominant fatty acid in egg yolks in all treated groups, being higher in the TO and TO/CLA than in the LO, LO/CLA, and CLA-treated groups during the whole period of experiment. The CLA isomers in egg yolks appeared earlier at one week of feeding CLA-added diets (Table 6). The CLA in combination with either TO or LO was equally incorporated into the egg yolks, but to a lesser extent $(\mathrm{P}<0.05)$ compared with the CLA-treated group. No CLA isomers were detected in egg yolk from layers fed the diet devoid of CLA during the experimental period. Dietary LO alone or in combination with CLA increased the ALA content in egg yolks, but the concentration was higher $(\mathrm{P}<0.05)$ in the former than in the latter. Consequently, the levels of total $\omega-3$ and $\omega-3: \omega-6$ ratio were higher $(\mathrm{P}<0.05)$ by LO supplementation compared with the TO or TO/CLA supplementations. The EPA and DHA levels were highest in the LO followed by the LO/CLA-treated group. Total saturated fatty acid (SFA) was higher $(\mathrm{P}<0.05)$ in the LO and LO/CLA compared with the TO or TO/CLA-treated groups. On the other hand, total monounsaturated fatty acid (MUFA) was higher in the TO and TO/CLA-treated groups compared with the groups receiving LO, LO/CLA, and CLA. Total SFA and total MUFA contents in egg yolks were altered at one week of feeding the experimental diets and kept thereafter. On the other hand, total polyunsaturated fatty acid (PUFA) contents in egg yolks took longer to be altered

Table 3 - Effect of dietary fats and conjugated linoleic acid (CLA) on laying performance, relative liver weight, and the activity of serum enzymes in layers

\begin{tabular}{lcccc}
\hline Item & TO & TO/CLA & LO & CLA \\
\hline Feed intake (g/day/bird) & $112.3 \pm 0.52^{1}$ & $112.5 \pm 0.69$ & $110.8 \pm 0.89$ & $110.6 \pm 1.55$ \\
Egg production rate (\%) & $90.75 \pm 1.75$ & $89.70 \pm 2.53$ & $90.85 \pm 1.13$ & $88.85 \pm 1.96$ \\
Egg weight (g/egg) & $65.03 \pm 0.51$ & $64.68 \pm 0.53$ & $63.93 \pm 0.35$ & $64.60 \pm 0.29$ \\
Daily egg mass & $59.40 \pm 1.59$ & $57.40 \pm 2.03$ & $57.65 \pm 1.33$ & $57.53 \pm 1.76$ \\
Liver weight (g/100 g BW) & $2.11 \pm 0.09$ & $2.01 \pm 0.11$ & $2.17 \pm 0.09$ & $2.17 \pm 0.08$ \\
GOT (mg/dL) & $157.46 \pm 8.37$ & $152.50 \pm 6.63$ & $150.82 \pm 6.37$ & $150.22 \pm 6.85$ \\
GPT (mg/dL) & $9.50 \pm 1.56$ & $9.73 \pm 1.07$ & $9.68 \pm 2.65$ & $9.14 \pm 1.19$
\end{tabular}

BW - body weight; GOT - glutamic oxaloacetic transaminase; GPT - glutamic pyruvic transaminase.

TO: $2 \%$ tallow in diet; TO/CLA: $1 \%$ tallow and 1\% CLA in diet; LO: $2 \%$ linseed oil in diet; LO/CLA: $1 \%$ linseed oil and $1 \%$ CLA in diet; CLA: $2 \%$ CLA in diet.

${ }^{1}$ Values are expressed as mean \pm standard error $(\mathrm{n}=4 /$ treatment for feed intake, egg production, egg weight, and daily egg mass; $\mathrm{n}=10 /$ treatment for liver weight, GOT, and GPT). 
and was elevated $(\mathrm{P}<0.05)$ in the egg yolks of the $\mathrm{LO}$ and LO/CLA-treated groups compared with the ones receiving TO, TO/CLA and CLA only at 28 days.

\section{Discussion}

The current experiment was performed without problem, and no mortality was recorded during the experimental period. No feed refusal was noted. In this study, we used 50-week-old laying hens. It should be pointed out that age per se of laying hens affected egg weight and/or fatty acid composition of egg yolks (Nielsen, 1998).
The lack of effect on the parameters such as laying performance, egg quality, egg yolk lipids, and blood components could be due to our experimental design, in which all diets had equal contents of energy and essential amino acids and low inclusion fat/CLA levels. In line with our finding, Cherian et al. (2007) observed no differences in eggshell weight, yolk weight, and Haugh unit in laying hens fed diets containing CLA or fish oil. In addition, Yin et al. (2008) failed to observe the cholesterol lowering effect of CLA in laying hens, which corroborates our finding. The observation that glutamic oxaloacetic transaminase levels in serum samples did not differ across the treatments

Table 4 - Effect of dietary fats and conjugated linoleic acid on eggshell qualities in layers

\begin{tabular}{lcccc}
\hline Item & TO & TO/CLA & LO & COA $/$ CLA \\
\hline Eggshell strength $\left(\mathrm{kg} / \mathrm{cm}^{2}\right)$ & $3.17 \pm 0.07^{1}$ & $3.21 \pm 0.08$ & $3.13 \pm 0.08$ & $3.13 \pm 0.07$ \\
Eggshell thickness $(\mu \mathrm{m})$ & $379 \pm 3.0$ & $385 \pm 3.0$ & $386 \pm 3.0$ & $388 \pm 2.9$ \\
Yolk color, RCF & $7.48 \pm 0.05$ & $7.46 \pm 0.06$ & $7.40 \pm 0.06$ & $7.38 \pm 0.06$ \\
Haugh unit & $62.41 \pm 1.16$ & $61.74 \pm 0.95$ & $62.65 \pm 0.94$ & $62.07 \pm 0.94$ \\
\hline
\end{tabular}

RCF - Roche yolk color fan.

TO: $2 \%$ tallow in diet; TO/CLA: $1 \%$ tallow and 1\% CLA in diet; LO: $2 \%$ linseed oil in diet; LO/CLA: $1 \%$ linseed oil and $1 \%$ CLA in diet; CLA: $2 \%$ CLA in diet.

${ }^{1}$ Values are expressed as mean \pm standard error $(n=4 /$ treatment $)$.

Table 5 - Effect of dietary fats and conjugated linoleic acid on lipids in egg yolk of layers

\begin{tabular}{lcccc}
\hline Item & TO & TO/CLA & LO & LO/CLA \\
\hline Total cholesterol (mg/g yolk) & $12.8 \pm 0.31^{1}$ & $12.8 \pm 0.28$ & $12.6 \pm 0.62$ & $12.7 \pm 0.28$ \\
Triacylglycerol (mg/g yolk) & $260.5 \pm 4.07$ & $257.2 \pm 10.52$ & $253.9 \pm 6.03$ & $250.9 \pm 5.20$ \\
Phospholipid (mg/g yolk) & $85.7 \pm 3.41$ & $86.5 \pm 4.07$ & $89.3 \pm 3.31$ & $255.3 \pm 6.21$ \\
\hline
\end{tabular}

TO: $2 \%$ tallow in diet; TO/CLA: 1\% tallow and 1\% CLA in diet; LO: $2 \%$ linseed oil in diet; LO/CLA: $1 \%$ linseed oil and 1\% CLA in diet; CLA: $2 \%$ CLA in diet.

${ }^{1}$ Values are expressed as mean \pm standard error $(n=6$ for each diet).

Table 6 - Effect of dietary fats and conjugated fatty acid on the fatty acid composition of egg yolk at seven days of feeding $(\%$ of total fatty acids $)^{1}$

\begin{tabular}{|c|c|c|c|c|c|}
\hline Fatty acids ${ }^{2}$ & TO & $\mathrm{TO} / \mathrm{CLA}$ & $\mathrm{LO}$ & $\mathrm{LO} / \mathrm{CLA}$ & CLA \\
\hline C14:0 & $0.39 \pm 0.02 b$ & $0.32 \pm 0.01 b$ & $0.61 \pm 0.03 \mathrm{a}$ & $0.62 \pm 0.05 \mathrm{a}$ & $0.55 \pm 0.02 \mathrm{a}$ \\
\hline C16:0 & $25.27 \pm 0.23 b$ & $22.73 \pm 1.17 \mathrm{c}$ & $31.35 \pm 0.70 \mathrm{a}$ & $31.32 \pm 0.71 \mathrm{a}$ & $30.13 \pm 0.31 \mathrm{a}$ \\
\hline C16:1 $(\omega-7)$ & $2.67 \pm 0.17 \mathrm{a}$ & $2.27 \pm 0.15 b$ & $0.93 \pm 0.07 \mathrm{~d}$ & $1.33 \pm 0.11 \mathrm{c}$ & $1.31 \pm 0.10 \mathrm{c}$ \\
\hline C18:0 & $8.70 \pm 0.22 \mathrm{c}$ & $9.30 \pm 0.48 \mathrm{c}$ & $17.66 \pm 0.54 \mathrm{a}$ & $15.87 \pm 0.38 \mathrm{~b}$ & $15.91 \pm 0.50 \mathrm{~b}$ \\
\hline C18:1 ( $\omega-9)$ & $42.17 \pm 0.92 \mathrm{a}$ & $41.96 \pm 0.67 \mathrm{a}$ & $22.66 \pm 0.80 \mathrm{c}$ & $27.79 \pm 0.93 b$ & $27.81 \pm 0.71 b$ \\
\hline $\mathrm{C} 18: 2(\omega-6)$ & $11.73 \pm 0.86$ & $12.51 \pm 0.88$ & $15.37 \pm 0.62$ & $13.74 \pm 0.82$ & $12.93 \pm 1.04$ \\
\hline 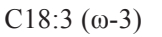 & $0.26 \pm 0.05 \mathrm{~d}$ & $0.14 \pm 0.01 \mathrm{~d}$ & $1.83 \pm 0.11 \mathrm{a}$ & $1.13 \pm 0.07 \mathrm{~b}$ & $0.62 \pm 0.05 \mathrm{c}$ \\
\hline Total CLA & NDc & $1.11 \pm 0.10 \mathrm{~b}$ & NDc & $1.06 \pm 0.04 b$ & $1.80 \pm 0.07 \mathrm{a}$ \\
\hline $\mathrm{C} 20: 1(\omega-9)$ & $0.22 \pm 0.01 \mathrm{a}$ & $0.16 \pm 0.01 b$ & $0.16 \pm 0.01 b$ & $0.16 \pm 0.01 b$ & $0.13 \pm 0.01 \mathrm{c}$ \\
\hline C20:3 ( $\omega-6)$ & $0.14 \pm 0.01$ & $0.17 \pm 0.02$ & $0.17 \pm 0.02$ & $0.15 \pm 0.01$ & $0.13 \pm 0.01$ \\
\hline $\mathrm{C} 20: 4(\omega-6)$ & $1.80 \pm 0.06 \mathrm{a}$ & $1.28 \pm 0.06 \mathrm{c}$ & $1.43 \pm 0.04 \mathrm{bc}$ & $1.52 \pm 0.04 \mathrm{~b}$ & $1.35 \pm 0.08 b c$ \\
\hline C20:5 ( $\omega-3)$ & $0.08 \pm 0.01$ & $0.10 \pm 0.01$ & $0.11 \pm 0.01$ & $0.07 \pm 0.01$ & $0.07 \pm 0.01$ \\
\hline$C 22: 6(\omega-3)$ & $0.59 \pm 0.02$ & $0.73 \pm 0.10$ & $0.78 \pm 0.05$ & $0.66 \pm 0.06$ & $0.60 \pm 0.04$ \\
\hline Total SFA & $34.36 \pm 0.40 c$ & $32.34 \pm 1.32 \mathrm{c}$ & $49.62 \pm 0.92 \mathrm{a}$ & $47.80 \pm 0.98 \mathrm{ab}$ & $46.60 \pm 0.75 b$ \\
\hline Total MUFA & $45.06 \pm 1.07 \mathrm{a}$ & $44.39 \pm 0.73 a$ & $23.75 \pm 0.80 \mathrm{c}$ & $29.28 \pm 0.94 b$ & $29.25 \pm 0.76 b$ \\
\hline Total PUFA & $14.69 \pm 0.93$ & $16.10 \pm 0.98$ & $19.74 \pm 0.75$ & $18.40 \pm 0.84$ & $17.56 \pm 1.06$ \\
\hline Total $\omega-6$ & $13.75 \pm 0.90$ & $14.03 \pm 0.92$ & $17.03 \pm 0.64$ & $15.48 \pm 0.81$ & $14.47 \pm 1.06$ \\
\hline Total $\omega-3$ & $0.93 \pm 0.05 \mathrm{~d}$ & $0.97 \pm 0.10 \mathrm{~d}$ & $2.72 \pm 0.12 \mathrm{a}$ & $1.86 \pm 0.08 b$ & $1.29 \pm 0.07 \mathrm{c}$ \\
\hline$\omega-3: \omega-6$ & $0.07 \pm 0.01 \mathrm{~d}$ & $0.07 \pm 0.01 \mathrm{~d}$ & $0.16 \pm 0.01 \mathrm{a}$ & $0.12 \pm 0.01 \mathrm{~b}$ & $0.09 \pm 0.01 \mathrm{c}$ \\
\hline
\end{tabular}

TO: $2 \%$ tallow in diet; TO/CLA: 1\% tallow and 1\% CLA in diet; LO: 2\% linseed oil in diet; LO/CLA: 1\% linseed oil and 1\% CLA in diet; CLA: $2 \%$ CLA in diet.

SFA - saturated fatty acids; MUFA - monounsaturated fatty acids; PUFA - polyunsaturated fatty acids; ND - not detected.

${ }_{1}^{1}$ Mean \pm standard error $(n=6 /$ treatment $)$.

${ }^{2}$ Number of carbon atom: number of double bonds, followed by the position of the first double bond relative to the methyl end.

a-d - Mean values in a row with different letters are significantly different $(\mathrm{P}<0.05)$. 
Table 7 - Effect of dietary fats and conjugated fatty acid on the fatty acid composition of egg yolk at 28 days of feeding (\% of total fatty acids $)^{1}$

\begin{tabular}{|c|c|c|c|c|c|}
\hline Fatty acid ${ }^{2}$ & $\mathrm{TO}$ & TO/CLA & LO & $\mathrm{LO} / \mathrm{CLA}$ & CLA \\
\hline C14:0 & $0.38 \pm 0.02$ & $0.40 \pm 0.01$ & $0.43 \pm 0.03$ & $0.50 \pm 0.05$ & $0.44 \pm 0.01$ \\
\hline C16:0 & $23.27 \pm 0.48$ & $23.63 \pm 0.52$ & $25.01 \pm 0.25$ & $27.29 \pm 1.40$ & $26.94 \pm 0.40$ \\
\hline C16:1 ( $\omega-7)$ & $2.38 \pm 0.33$ & $2.41 \pm 0.15$ & $2.55 \pm 0.17$ & $2.14 \pm 0.27$ & $1.97 \pm 0.13$ \\
\hline C18:0 & $9.70 \pm 0.61 \mathrm{c}$ & $9.05 \pm 0.46 \mathrm{c}$ & $13.27 \pm 1.67 \mathrm{~b}$ & $13.52 \pm 0.90 \mathrm{~b}$ & $16.52 \pm 0.26 \mathrm{a}$ \\
\hline 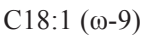 & $44.35 \pm 0.28 \mathrm{a}$ & $44.59 \pm 0.57 \mathrm{a}$ & $26.63 \pm 1.44 \mathrm{c}$ & $30.41 \pm 1.05 b$ & $30.06 \pm 1.29 b$ \\
\hline 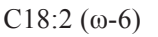 & $11.23 \pm 0.16 \mathrm{~b}$ & $9.49 \pm 0.43 c$ & $13.63 \pm 0.90 \mathrm{a}$ & $13.53 \pm 0.70 \mathrm{a}$ & $11.74 \pm 0.20 \mathrm{~b}$ \\
\hline C18:3 ( $\omega-3)$ & $0.17 \pm 0.01 \mathrm{~d}$ & $0.17 \pm 0.01 \mathrm{~d}$ & $2.15 \pm 0.12 \mathrm{a}$ & $1.33 \pm 0.10 \mathrm{~b}$ & $0.43 \pm 0.07 \mathrm{c}$ \\
\hline Total CLA & NDc & $1.42 \pm 0.06 \mathrm{~b}$ & NDc & $1.54 \pm 0.09 b$ & $2.34 \pm 0.21 \mathrm{a}$ \\
\hline C20:1 ( $\omega-9)$ & $0.19 \pm 0.02$ & $0.16 \pm 0.01$ & $0.18 \pm 0.03$ & $0.15 \pm 0.01$ & $0.13 \pm 0.01$ \\
\hline $\mathrm{C} 20: 3(\omega-6)$ & $0.18 \pm 0.01$ & $0.17 \pm 0.01$ & $0.13 \pm 0.01$ & $0.13 \pm 0.01$ & $0.13 \pm 0.01$ \\
\hline $\mathrm{C} 20: 4(\omega-6)$ & $2.22 \pm 0.08 \mathrm{a}$ & $1.78 \pm 0.13 b$ & $1.27 \pm 0.04 \mathrm{c}$ & $1.39 \pm 0.04 \mathrm{c}$ & $1.33 \pm 0.03 \mathrm{c}$ \\
\hline $\mathrm{C} 20: 5(\omega-3)$ & $0.10 \pm 0.01 \mathrm{c}$ & $0.09 \pm 0.01 \mathrm{~cd}$ & $0.18 \pm 0.01 \mathrm{a}$ & $0.13 \pm 0.01 b$ & $0.07 \pm 0.01 \mathrm{~d}$ \\
\hline $\mathrm{C} 22: 6(\omega-3)$ & $0.48 \pm 0.03 \mathrm{~d}$ & $0.71 \pm 0.07 \mathrm{bc}$ & $1.10 \pm 0.07 \mathrm{a}$ & $0.81 \pm 0.04 \mathrm{~b}$ & $0.58 \pm 0.03 \mathrm{~cd}$ \\
\hline Total SFA & $33.35 \pm 0.14 \mathrm{c}$ & $33.09 \pm 0.39 \mathrm{c}$ & $38.71 \pm 1.51 \mathrm{~b}$ & $41.31 \pm 2.03 \mathrm{ab}$ & $43.89 \pm 0.61 \mathrm{a}$ \\
\hline Total MUFA & $46.93 \pm 0.30 \mathrm{a}$ & $47.16 \pm 0.45 \mathrm{a}$ & $29.36 \pm 1.46 \mathrm{c}$ & $32.69 \pm 1.23 b$ & $32.16 \pm 1.19 b c$ \\
\hline Total PUFA & $14.46 \pm 0.15 \mathrm{c}$ & $13.92 \pm 0.49 \mathrm{c}$ & $18.53 \pm 0.92 \mathrm{a}$ & $18.92 \pm 0.71 \mathrm{a}$ & $16.68 \pm 0.24 b$ \\
\hline Total $\omega-6$ & $13.72 \pm 0.14$ & $11.53 \pm 0.44$ & $15.11 \pm 0.90$ & $15.11 \pm 0.70$ & $13.26 \pm 0.20$ \\
\hline Total $\omega-3$ & $0.74 \pm 0.02 \mathrm{~d}$ & $0.97 \pm 0.07 \mathrm{~cd}$ & $3.43 \pm 0.11 \mathrm{a}$ & $2.27 \pm 0.09 b$ & $1.08 \pm 0.08 \mathrm{c}$ \\
\hline$\omega-3: \omega-6$ & $0.06 \pm 0.01 \mathrm{~d}$ & $0.08 \pm 0.01 \mathrm{c}$ & $0.23 \pm 0.01 \mathrm{a}$ & $0.15 \pm 0.01 b$ & $0.08 \pm 0.01 \mathrm{c}$ \\
\hline
\end{tabular}

TO: $2 \%$ tallow in diet; TO/CLA: 1\% tallow and 1\% CLA in diet; LO: $2 \%$ linseed oil in diet; LO/CLA: $1 \%$ linseed oil and $1 \%$ CLA in diet; CLA: $2 \%$ CLA in diet.

SFA - saturated fatty acids; MUFA - monounsaturated fatty acids; PUFA - polyunsaturated fatty acids; ND - not detected.

${ }^{1}$ Mean \pm standard error $(n=6 /$ treatment $)$.

${ }^{2}$ Number of carbon atom: number of double bonds, followed by the position of the first double bond relative to the methyl end.

a-d - Mean values in a line with different letters are significantly different $(\mathrm{P}<0.05)$.

indicates the absence of negative dietary effects in laying hens.

Our study clearly shows that diet-origin CLA or $\omega-3$ fatty acids, alone or in combination, were readily and efficiently transferred into egg yolk, which well corroborates previous reports (Chamruspollert and Sell, 1999; Du et al., 1999; Fraeye et al., 2012). It is well known that dietary intake of $\omega-3$ PUFA is effective in lowering blood lipids, inflammatory disease, and the risk of cardiac disease (Grundy and Denke, 1990). The nutritionally valuable $\omega-3$ PUFA are of ALA, EPA, and DHA. The main $\omega-3$ fatty acid of vegetable origin is ALA, but both EPA and DHA are rich in marine oils. Indeed, it has been reported that dietary $\omega-3$ fatty acid sources, such as linseed oil and full-fat linseed (Phetteplace and Watkins, 1989; Olomu and Baracos, 1991), fish oil (Scaife et al., 1994), and fish meal (Hulan et al., 1989), can produce $\omega-3$ PUFA enriched eggs in laying hens. In this study, we used ALA-rich LO to enrich the amounts of $\omega-3$ PUFA in eggs since ALA is the precursor of EPA and DHA. The conversion of dietary ALA into EPA and DHA is inefficient (Beynen, 2004), but dietary LO vs. TO significantly enriched ALA, EPA, and DHA in eggs compared with the LO-free diets-fed groups. This could contribute to partially fulfill the daily DHA requirement of humans by consuming such eggs. This is considered important, as modern diets consumed by humans are low in $\omega-3$ PUFA but high in $\omega-6$ PUFA due to increasing intake of vegetable oils that are relatively high in $\omega-6$ fatty acids. It is well established from the clinical studies that the higher ratio of $\omega-6: \omega-3$ fatty acids due to higher intake of $\omega-6$ fatty acids, but lower intake of $\omega-3$ fatty acids, is closely associated with promoting the pathogenesis of diseases such as cardiovascular disease, cancer, and inflammatory and autoimmune diseases (Jeong et al., 2014). It can be argued that $\omega-3$ PUFA-enriched eggs may be susceptible to lipid oxidation and become rancid. However, this phenomenon is less likely as the basal diet contained sufficient amounts of antioxidants (vitamin E, vitamin C, and ethoxyquin). It has been reported that $\omega-3$ PUFA in enriched eggs was stable during storage in the presence of antioxidants (Ren et al., 2013; Lamas et al., 2016).

In addition, we confirmed that dietary CLA was incorporated into the egg yolks (Chamruspollert and Sell, 1999; Jones et al., 2000; Du and Ahn, 2002) and increased SFA but reduced MUFA in egg yolks (Du and Ahn, 2002). The CLA-induced effect on fatty acid profile was more pronounced when dietary LO vs. TO was used. In contrast to previous findings (Grobas et al., 2001; Celebi and Macit, 2009), dietary LO vs. TO significantly increased SFA contents but reduced MUFA in egg yolks, which would negatively impact human health. The clear explanation on the conflicting results is not readily available at this stage, which awaits to be answered. Although SFA consumption is recommended to be restricted, the association between 
SFA consumption and the risk of cardiovascular disease is still under controversy (Nettleton et al., 2016).

\section{Conclusions}

Dietary linseed oil or conjugated linoleic acid at the level of $1 \%$ in layer diet enhances the incorporation of the respective fatty acids into egg yolks, and a mixture of linseed oil and conjugated linoleic acid added to the diet of laying hens equally increase both $\omega-3$ fatty acids and conjugated linoleic acid in the egg yolks. Thus, feeding layers dietary sources of conjugated linoleic acid in combination with linseed oil can be considered an effective way to enrich beneficial conjugated linoleic acid and $\omega-3$ polyunsaturated fatty acids in eggs.

\section{Acknowledgments}

This paper was supported by Konkuk University in 2017.

\section{References}

An, B. K.; Shinn, K. H.; Kobayashi, Y.; Tanaka, K. and Kang, C. W. 2003. Excessive dietary conjugated linoleic acid affects hepatic lipid content and muscular fatty acid composition in young chicks. Asian-Australasian Journal of Animal Sciences 16:1171-1176.

An, B. K.; Nishiyama, H.; Tanaka, K.; Ohtani, S.; Iwata, T.; Tsutsumi, K. and Kasai, M. 1997. Dietary safflower phospholipid reduces liver lipids in laying hens. Poultry Science 76:689-695.

Bauman, D. E.; Barbano, D. M.; Dwyer, D. A. and Griinari, and J. M. 2000. Technical note: production of butter with enhanced conjugated linoleic acid for use in biomedical studies with animal models. Journal of Dairy Science 83:2242-2245.

Beynen, A. C. 2004. Fatty acid composition of eggs produced by hens fed diets containing groundnut, soya bean or linseed. NJAS Wageningen Journal of Life Science 52:3-10.

Celebi, S. and Macit, M. 2009. Effects of feeding tallow and plant fat to laying hens on performance, egg quality and fatty acid composition of egg yolk. Journal of Applied Animal Research $36: 49-56$.

Chamruspollert, M. and Sell, J. L. 1999. Transfer of dietary conjugated linoleic acid to egg yolks of chickens. Poultry Science 78:1138-1150.

Cherian, G.; Gonzalez, D.; Ryu, K. S. and Goeger, M. P. 2007. Longterm feeding of conjugated linoleic acid and fish oil to laying hens: Effects on hepatic histopathology, egg quality, and lipid components. Journal of Applied Poultry Research 16:420-428.

Du, M. and Ahn, D. U. 2002. Effect of dietary conjugated linoleic acid on the growth rate of live birds and on the abdominal fat content and quality of broiler meat. Poultry Science 81:428-433.

Du, M.; Ahn, D. U and Sell, J. L. 1999. Effect of dietary conjugated linoleic acid on the composition of egg yolk lipids. Poultry Science 78:1639-1645.

Elkin, R. G. 2007. Reducing shell egg cholesterol content. II. Review of approaches utilizing non-nutritive dietary factors or pharmacological agents and an examination of emerging strategies. World's Poultry Science Journal 63:5-31.

Elkin, R. G.; Ying, Y. and Harvatine, K. J. 2015. Feeding laying hens stearidonic acid-enriched soybean oil, as compared to flaxseed oil, more efficiently enriches eggs with very long-chain n-3 polyunsaturated fatty acids. Journal of Agriculture and Food Chemistry 63:2789-2797.

Folch, J.; Lees, M. and Sloane-Stanley, G. H. 1957. A simple method for the isolation and purification of total lipids from animal tissue. Journal of Biological Chemistry 226:497-509.

Fraeye, I.; Bruneel, C.; Lemahieu, C.; Buyse, J.; Muylaert, K. and Foubert, I. 2012. Dietary enrichment of eggs with omega-3 fatty acids: A review. Food Research International 48:961-969.

Grobas, S.; Mendez, J.; Lazaro, R.; de Blas, C. and Mateos, G. G. 2001. Influence of source and percentage of fat added to diet on performance and fatty acid composition of egg yolks of two strains of laying hens. Poultry Science 80:1171-1179.

Grundy, S. M. and Denke, M. A. 1990. Dietary influences on serum lipids and lipoproteins. Journal of Lipid Research 31:1149-1172.

Hargis, P. S. and Van Elswyk, M. E. 1993. Manipulating the fatty acid composition of poultry meat and eggs for the health conscious consumer. World's Poultry Science Journal 49:251-264.

Haugh, R. R. 1937. The Haugh unit for measuring egg quality. US Egg Poultry Magazine 43:572-573.

Hulan, H. W.; Ackman, R. G.; Ratnayake, W. M. N. and Proudfoot, F. G. 1989. Omega-3 fatty acid levels and general performance of commercial broilers fed practical levels of redfish meal. Poultry Science 68:153-162.

Hur, S. J.; Kim, D. H.; Chun, S. C. and Lee, S. K. 2013a. Effects of dietary conjugated linoleic acid and biopolymer encapsulation on lipid metabolism in mice. International Journal of Molecular Sciences 14:6848-6862.

Hur, S. J.; Kim, Y. C.; Choi, I. and Lee, S. K. 2013b. The effects of biopolymer encapsulation on total lipids and cholesterol in egg yolk during in vitro human digestion. International Journal of Molecular Sciences 14:16333-16347.

Ip, C.; Banni, S.; Angioni, E.; Carta, G.; McGinley, J.; Thompson, H. J.; Barbano, D. and Bauman, D. 1999. Conjugated linoleic acid-enriched butter fat alters mammary gland morphogenesis and reduces cancer risk in rats. Journal of Nutrition 129:2135-2142.

Jeong, M.; Cho, J.; Shin, J. I.; Jeon, Y. J.; Kim, J. H.; Lee, S. J.; Kim, E. S. and Lee, K. 2014. Hempseed oil induces reactive oxygen species-and C/EBP homologous protein-mediated apoptosis in MH7A human rheumatoid arthritis fibroblast-like synovial cells. Journal of Ethnopharmacology 154:745-752.

Jones, S.; Ma, D. W.; Robinson, F. E.; Field, C. J. and Clandinin, M. T. 2000. Isomers of conjugated linoleic acid (CLA) are incorporated into egg yolk lipids by CLA-fed laying hens. Journal of Nutrition 130:2002-2005.

Lamas, A.; Anton, X.; Miranda, J. M.; Roca-Saavedra, P.; CardelleCobas, A.; Rodriguez, J. A.; Franco, C. M. and Cepeda, A. 2016. Technological development of functional egg products by an addition of n-3 polyunsaturated-fatty-acid-enriched oil. CyTA Journal of Food 14:289-295.

Miranda, J. M.; Anton, X.; Redondo-Valbuena, C.; Roca-Saavedra, P.; Rodriguez, J. A.; Lamas, A.; Franco, C. M. and Cepeda, A. 2015. Egg and egg-derived foods: effects on human health and use as functional foods. Nutrients 7:706-729.

NRC - National Research Council. 1994. Nutrients requirements of poultry. 9th ed. National Academic Press, Washington, DC.

Nettleton, J. A.; Lovegrove, J. A.; Mensink,R. P. and Schwab, U. 2016. Dietary fatty acids: is it time to change the recommendations? Annals of Nutrition and Metabolism 68:249-257. 
Nielsen, H. 1998. Hen age and fatty acid composition of egg yolk lipid. British Poultry Science 39:53-56.

Nile, S. H. and Park, S. W. 2013. Fatty acid composition and antioxidant activity of groundnut (Arachis hypogaea L.) products. Food Science and Technology Research 19:957-962.

Oh, J. J.; Lee, J. S.; Lim, J. N.; Wang, T.; Kim, S. H. and Lee, H. G. 2014. Trans vaccenic acid (trans-11 18:1), a precursor of cis-9, trans-11-conjugated linoleic acid, exerts a direct anti-carcinogenic function in T47D breast carcinoma cells. Food Science and Biotechnology 23:641-646.

Olomu, J. M. and Baracos, V. E. 1991. Influence of dietary flaxseed oil on the performance, muscle protein deposition, and fatty acid composition of broiler chicks. Poultry Science 70:1403-1411.

Phetteplace, H. W. and Watkins, B. A. 1989. Effects of various n-3 lipid sources on fatty acid compositions in chicken tissues. Journal of Food Composition and Analysist 2:104-117.

Raes, K.; Huyghebaert, G.; De Smet, S.; Nollet, L.; Arnouts, S. and Demeyer, D. 2002. The deposition of conjugated linoleic acids in eggs of laying hens fed diets varying in fat level and fatty acid profile. Journal of Nutrition 132:182-189.

Ren, Y.; Perez, T. I.; Zuidhof, M. J.; Renema, R. A. and Wu, J. 2013. Oxidative stability of omega-3 polyunsaturated fatty acids enriched eggs. Journal of Agricultural and Food Chemistry 27:11595-11602.

Scaife, J. R.; Moyo, J.; Galbraith, H.; Michie, W. Campbell, V. 1994. Effect of different dietary supplemental fats and oils on the tissue fatty acid composition and growth of female broilers. British Poultry Science 35:107-118.

Takenoyama, S.; Kawahara, S.; Murata, H. and Yamauchi, K. 1999. Investigation of some preparation procedures of fatty acid methyl esters for capillary gas-liquid chromatographic analysis of conjugated linoleic acid in meat. Animal Science Journal 70:336-342.

Wang, T. and Lee, H. G. 2015. Advances in research on cis-9, trans-11 conjugated linoleic acid: a major functional conjugated linoleic acid isomer. Critical Reviews in Food Science and Nutrition 55:720-731.

Wang, T.; Lim, J. N.; Choi, S. H.; Kang, H. S. and Lee, H. G. 2013. Comparative studies on derivatization methods of single or mixed fatty acids. Food Science and Biotechnology 22:1573-1579.

Wang, T.; Lim, J. N.; Lee, J. S.; Lee, S. B; Hwang, J. H.; Jung, U. S.; Kim, M. J.; Hwang, D. Y.; Lee, S. R.; Roh, S. G. and Lee, H. G. 2015. Effects of dietary trans-9 octadecenoic acid, trans-11 vaccenic acid and cis-9, trans-11 conjugated linoleic acid in mice. Molecular Medicine Reports 12:3200-3206.

Yamamoto, T.; Juneja, L. R.; Hatta, H. and Kim, M. J. 1997. Hen eggs. Their basic and applied science. CRC Press Inc., Boca Raton, FL.

Yamasaki, M.; Kishihara, K.; Mansho, K.; Ogino, Y.; Kasai, M.; Sugano, M.; Tachibana, H. and Yamada, K. 2000. Dietary conjugated linoleic acid increases immunoglobulin productivity of Sprague-Dawley rat spleen lymphocytes Biosicence, Biotechnology, and Biochemistry 64:2159-2164.

Yin, J. D.; Shang, X. G.; Li, D. F.; Wang, F. L.; Guan, Y. F. and Wang, Z. Y. 2008. Effects of dietary conjugated linoleic acid on the fatty acid profile and cholesterol content of egg yolks from different breeds of layers. Poultry Science 87:284-290.

Zazpe, I.; Beunza, J. J.; Bes-Rastrollo, M.; Warnberg, J.; De La FuenteArrillaga, C.; Bentito, S.; Vazquez, Z. and Martinez-Gonzalez, M. A. 2011. Egg consumption and risk of cardiovascular disease in the SUN project. European Journal of Clinical Nutrition 65:676-682. 